\title{
Editorial:
}

\section{Large deformation analysis in geohazards and geotechnics}

Zhen-yu YIN ${ }^{1}$, Guest Editor-in-Chief

Yin-fu JIN ${ }^{1}$, Xue ZHANG ${ }^{2}$, Guest Editors

${ }^{I}$ Department of Civil and Environmental Engineering, The Hong Kong Polytechnic University, Kowloon, Hong Kong, China

${ }^{2}$ Department of Civil Engineering and Industrial Design, University of Liverpool, Liverpool, L69 7ZX, UK

E-mail: zhenyu.yin@polyu.edu.hk; yinfu.jin9019@gmail.com; xue.zhang2@liverpool.ac.uk

https://doi.org/10.1631/jzus.A21LDGG1

For geohazards and geotechnics, numerous problems involve large deformation, such as the installation of foundations (Jin YF et al., 2018a), landslides (Jin YF et al., 2020b), debris flow (Dai et al., 2017), collapse of underground structures (Zhang et al., 2019), and the formation of sinkholes (Barandiarán Villegas, 2018). Benefitting from the sustained development of computing power, numerical simulations have become useful analytical methods in geomechanics and related fields.

Among those numerical methods, the finite element method (FEM) features prominently in engineering practice (Rao, 2017). For conventional FEM, however, excessive deformation may result in mesh distortion with numerical inaccuracy, even to the point of making calculation impossible. To solve this issue and enable application to large deformation analysis, different numerical approaches have been successfully developed. These approaches can be generally classified into three categories: discontinuous, continuous, and coupled continuousdiscontinuous (Zhang, 2014). One of the most popular discontinuous approaches is discrete element method (DEM) (Cundall and Strack, 1979; Calvetti, 2008). Practical applications of this kind of method are limited by their high computational cost, although

\footnotetext{
* Project supported by the Research Impact Fund (RIF) Project of Hong Kong Special Administrative Region Government of China (No. R5037-18)

(DD ORCID: Zhen-yu YIN, https://orcid.org/0000-0003-4154-7304 (C) Zhejiang University Press 2021
}

their robustness and potential have been demonstrated in academic exercises. Continuous approaches can be sub-divided into three groups: (1) mesh-based methods, such as the arbitrary Lagrangian-Eulerian (ALE) (Belytschko et al., 2013) and the remeshing and interpolation technique with small strain (RITSS) (Hu and Randolph, 1998); (2) mesh-free particle methods, such as the smoothed particle hydrodynamics (SPH) method (Lucy, 1977), element-free Galerkin (EFG) method (Belytschko et al., 1994), and reproducing kernel particle method (RKPM) (Chen et al., 1996); (3) mesh-based particle methods, such as the material point method (MPM) (Harlow, 1964) and particle finite element method (PFEM) (Oñate et al., 2004; Zhang et al., 2013) and its variants-strain smoothed PFEM (Zhang et al., 2018; Yuan et al., 2019; Jin YF et al., 2020a, 2020b, 2021a, 2021b; Guo and Yang, 2021; Meng et al., 2021). The coupled Eulerian-Lagrangian (CEL) is another mesh-based method (Qiu et al., 2011; Hamann et al., 2015), similar to MPM, and requires a background mesh. The third category of methods used for large deformation analysis, the coupled continuous-discontinuous approach, includes finite difference method (FDM)-DEM (Yin et al., 2020), PFEM-DEM (Guo et al., 2021), and MPM-DEM (Liang and Zhao, 2019). Significant developments have been made in this field, which has attracted more attention in recent years due to consideration of the physics of geomaterials.

This special issue contains original research articles on the application of numerical methods to large deformation analysis of geohazards and geotechnics. Focal points of the issue include innovative uses of: (1) mesh-based methods, (2) mesh-free particle methods, (3) mesh-based particle methods, (4) discontinuous numerical methods, and finally (5) practical applications of the above techniques, e.g. case studies and benchmarking exercises.

We invited prestigious scientists in the field to share their expertise and perspectives. The collected 
articles cover the various topics mentioned, and are briefly introduced as follows.

Shan et al. (2021) implemented a damping layer and dashpot absorbing boundary conditions (ABCs) into the MPM with slight adjustments. The feasibility of the $\mathrm{ABCs}$ was assessed through benchmark problems of 1D compression, submarine landslides impacting mudmat, and dynamic penetration of a pipeline. Velocity fluctuations induced by elastic wave propagation and the impact force fluctuations on structures were investigated at specific observation points. Based on accurate derivations of wave equations, the dashpot $\mathrm{ABC}$ was found to be more feasible than the damping layer $\mathrm{ABC}$ for free surfaces with a complex kinematic field. The impact forces predicted by the MPM with $\mathrm{ABCs}$ were verified by comparison with those estimated using a computational fluid dynamics approach.

Jin $\mathrm{Z}$ et al. (2021) proposed a novel numerical approach to study soil collapse involving large deformation. The approach combined a recently developed critical state-based sand model SIMSAND for describing complex sand mechanical behaviors (Jin YF et al., 2016, 2018a, 2018b, 2019), and the SPH method for dealing with large deformation. To demonstrate the high efficiency and accuracy of the proposed approach, a series of column collapses using DEM and considering the influence of particle shapes (i.e. spherical shape (SS), tetrahedral shape (TS), and elongated shape (ES)) were adopted as benchmarks and simulated by the proposed method. Compared with the results of DEM simulations and reference solutions derived by published collapse experiments, the runout distance and final height of specimens with different particle shapes simulated by SPH-SIMSAND were well characterized and incurred a lower computational cost. Comparisons showed that the novel SPH-SIMSAND approach is highly efficient and accurate for simulating collapse, and can be a useful numerical analytical tool for real scale engineering problems.

Zheng et al. (2021) adopted the CEL modelling technique to investigate the influence of a failed tunnel (FT) on an adjacent tunnel, termed an "influenced tunnel" (IT). The safety of the IT was analyzed in detail under different circumstances, such as different failure positions of the FT, different failure degrees of the FT, and different spatial relationships between the two tunnels. The simulation results indicated that the most adverse case may occur when the two tunnels are arranged as offsets, and when the IT is the upper tunnel. Under these circumstances, significant shear deformation may occur in the IT because it is located at the shear band of the FT.

$\mathrm{Qu}$ et al. (2021) investigated the effects of the cross-correlation between cohesion and the friction angle on the probability of slope failure and postfailure behavior (e.g. run-out distance, influence distance, and influence zone) using a random MPM. The study showed that the mesh size, strength reduction shape factor parameter, and residual strength all play critical roles in the calculated post-failure behavior of a slope. A stochastic Monte Carlo simulation was used to study the effects of cross-correlation between cohesion and the friction angle on the probability of slope failure, and its run-out distance, influence distance, influence zone, and sliding volume. The study showed that the MPM has great advantages compared with the FEM in handling large deformations.

Yuan et al. (2021) presented a quasi-static implicit generalized interpolation material point method (iGIMP) with B-bar approach for large deformation geotechnical problems. The iGIMP algorithm is an extension of the implicit material point method (iMPM). A global stiffness matrix was formed explicitly and the Newton-Raphson iterative method was used to solve the equilibrium equations. The generalized interpolation function was assigned to eliminate the inherent cell crossing noise within conventional MPM. For the first time, the B-bar approach was used to overcome volumetric locking in the standard GIMP method for near-incompressible non-linear geomechanics. The proposed iGIMP was tested and compared with iMPM and analytical solutions via a 1D column compression problem. Results highlighted the superiority of the iGIMP approach in reducing stress oscillations, thereby improving computational accuracy. Then, elasto-plastic slope stabilities and rigid footing problems were considered, to further illustrate the ability of the proposed method to overcome volumetric locking due to incompressibility. Results showed that the proposed iGIMP with B-bar approach can be used to simulate geotechnical problems with large deformations. 
Zhang et al. (2021) explored the failure mode of the interface layer under uniform corrosion, and the influence of different factors on the corrosion expansion cracking and shedding mode of a concrete cover. This was achieved by establishing a three-phase meso-scale model of concrete based on secondary development of ABAQUS, simulating the mechanical behavior of the interface transition zone (ITZ) using a cohesive element, and establishing a rust expansion cracking model for single and multiple rebars. The results showed that: (1) Under uniform rust expansion, concrete cracks are distributed in a cross pattern with a slightly shorter lower limb. (2) When the corrosion rate is low, the ITZ is not damaged; with an increase in the corrosion rate, the proportion of elements with tensile damage in the ITZ first increases and then decreases. (3) In the case of a single rebar, the larger the cover thickness, the higher the corrosion rate corresponding to ITZ failure, and the arrangement of the rebar has little influence on the ITZ failure mode. (4) In the case of multiple rebars, the concrete cover cracks when the rebar spacing is small, and wedge-shaped spalling occurs when the spacing is large.

We believe that this special issue provided a valuable platform for researchers and engineers to present and discuss recent developments in large deformation analysis in geotechnical engineering. The interdisciplinary connections between advanced numerical methods and geotechnics were well highlighted and expressed by the selected publications. We sincerely hope the new and advanced methods shared in this special issue will improve the understanding of approaches and strategies related to large deformation analysis, and promote the application of new methods in the field of geotechnical engineering. We expect the selected articles will promote discussion among scientific researchers, and inspire and inform readers of this journal.

\section{Contributors}

Zhen-yu YIN conceived and edited the draft of manuscript. Yin-fu JIN conducted the literature review and wrote the first draft of the manuscript. Xue ZHANG edited the draft of manuscript.

\section{Conflict of interest}

Zhen-yu YIN, Yin-fu JIN, and Xue ZHANG declare that they have no conflict of interest.

\section{References}

Belytschko T, Lu YY, Gu L, 1994. Element-free Galerkin methods. International Journal for Numerical Methods in Engineering, 37(2):229-256. https://doi.org/10.1002/nme.1620370205

Belytschko T, Liu WK, Moran B, et al., 2013. Nonlinear Finite Elements for Continua and Structures. John Wiley \& Sons, Hoboken, USA.

Calvetti F, 2008. Discrete modelling of granular materials and geotechnical problems. European Journal of Environmental and Civil Engineering, 12(7-8):951-965. https://doi.org/10.1080/19648189.2008.9693055

Chen JS, Pan CH, Wu CT, et al., 1996. Reproducing kernel particle methods for large deformation analysis of non-linear structures. Computer Methods in Applied Mechanics and Engineering, 139(1-4):195-227. https://doi.org/10.1016/S0045-7825(96)01083-3

Cundall PA, Strack OD, 1979. A discrete numerical model for granular assemblies. Geotechnique, 29:47-65.

Dai ZL, Huang Y, Cheng HL, et al., 2017. SPH model for fluid-structure interaction and its application to debris flow impact estimation. Landslides, 14(3):917-928. https://doi.org/10.1007/s10346-016-0777-4

Guo N, Yang ZX, 2021. NSPFEM2D: a lightweight 2D node-based smoothed particle finite element method code for modeling large deformation. Computers and $\mathrm{Ge}$ otechnics, 140:104484. https://doi.org/10.1016/j.compgeo.2021.104484

Guo N, Yang ZX, Yuan WH, et al., 2021. A coupled SPFEM/DEM approach for multiscale modeling of largedeformation geomechanical problems. International Journal for Numerical and Analytical Methods in Geomechanics, 45(6):648-667. https://doi.org/10.1002/nag.3175

Hamann T, Qiu G, Grabe J, 2015. Application of a coupled Eulerian-Lagrangian approach on pile installation problems under partially drained conditions. Computers and Geotechnics, 63:279-290. https://doi.org/10.1016/j.compgeo.2014.10.006

Harlow FH, 1964. The particle-in-cell computing method for fluid dynamics. Methods in Computational Physics, 3: 319-343.

Hu Y, Randolph MF, 1998. A practical numerical approach for large deformation problems in soil. International Journal for Numerical and Analytical Methods in Geomechanics, 22(5):327-350. https://doi.org/10.1002/(SICI)1096-9853(199805)22:5<3 27::AID-NAG920>3.0.CO;2-X

Jin YF, Yin ZY, Shen SL, et al., 2016. Selection of sand models and identification of parameters using an enhanced genetic algorithm. International Journal for $\mathrm{Nu}$ merical and Analytical Methods in Geomechanics, 40(8): 1219-1240. https://doi.org/10.1002/nag.2487

Jin YF, Yin ZY, Wu ZX, et al., 2018a. Identifying parameters of easily crushable sand and application to offshore pile 
driving. Ocean Engineering, 154:416-429.

https://doi.org/10.1016/j.oceaneng.2018.01.023

Jin YF, Yin ZY, Wu ZX, et al., 2018b. Numerical modeling of pile penetration in silica sands considering the effect of grain breakage. Finite Elements in Analysis and Design, 144:15-29. https://doi.org/10.1016/j.finel.2018.02.003

Jin YF, Yin ZY, Zhou WH, et al., 2019. Identifying parameters of advanced soil models using an enhanced transitional Markov chain Monte Carlo method. Acta Geotechnica, 14(6):1925-1947. https://doi.org/10.1007/s11440-019-00847-1

Jin YF, Yuan WH, Yin ZY, et al., 2020a. An edge-based strain smoothing particle finite element method for large deformation problems in geotechnical engineering. International Journal for Numerical and Analytical Methods in Geomechanics, 44(7):923-941. https://doi.org/10.1002/nag.3016

Jin YF, Yin ZY, Yuan WH, 2020b. Simulating retrogressive slope failure using two different smoothed particle finite element methods: a comparative study. Engineering Geology, 279:105870.

https://doi.org/10.1016/j.enggeo.2020.105870

Jin YF, Yin ZY, Li J, et al., 2021a. A novel implicit coupled hydro-mechanical SPFEM approach for modelling of delayed failure of cut slope in soft sensitive clay. Computers and Geotechnics, 140:104474. https://doi.org/10.1016/j.compgeo.2021.104474

Jin YF, Yin ZY, Zhou XW, et al., 2021b. A stable node-based smoothed PFEM for solving geotechnical large deformation 2D problems. Computer Methods in Applied Mechanics and Engineering, 387:114179. https://doi.org/10.1016/j.cma.2021.114179

Jin Z, Lu Z, Yang Y, 2021. Numerical analysis of column collapse by smoothed particle hydrodynamics with an advanced critical state-based model. Journal of Zhejiang University-SCIENCE A (Applied Physics \& Engineering), 22(11):882-893.

https://doi.org/10.1631/jzus.A2000598

Liang WJ, Zhao JD, 2019. Multiscale modeling of large deformation in geomechanics. International Journal for Numerical and Analytical Methods in Geomechanics, 43(5):1080-1114. https://doi.org/10.1002/nag.2921

Lucy LB, 1977. A numerical approach to the testing of the fission hypothesis. Astronomical Journal, 82:1013-1024. https://doi.org/10.1086/112164

Meng JJ, Zhang X, Utili S, et al., 2021. A nodal-integration based particle finite element method (N-PFEM) to model cliff recession. Geomorphology, 381:107666. https://doi.org/10.1016/j.geomorph.2021.107666

Oñate E, Idelsohn SR, Del Pin F, et al., 2004. The particle finite element method-an overview. International Journal of Computational Methods, 1(2):267-307. https://doi.org/10.1142/S0219876204000204
Qiu G, Henke S, Grabe J, 2011. Application of a coupled Eulerian-Lagrangian approach on geomechanical problems involving large deformations. Computers and Geotechnics, 38(1):30-39. https://doi.org/10.1016/j.compgeo.2010.09.002

Qu CX, Wang G, Feng KW, et al., 2021. Large deformation analysis of slope failure using material point method with cross-correlated random fields. Journal of Zhejiang University-SCIENCE A (Applied Physics \& Engineering), 22(11):856-869. https://doi.org/10.1631/jzus.A2100196

Rao SS, 2017. The Finite Element Method in Engineering, 6th Edition. Butterworth-Heinemann, Oxford, UK. https://doi.org/10.1016/C2016-0-01493-6

Shan ZG, Liao ZX, Dong YK, et al., 2021. Implementation of absorbing boundary conditions in dynamic simulation of the material point method. Journal of Zhejiang UniversitySCIENCE A (Applied Physics \& Engineering), 22(11): 870-881. https://doi.org/10.1631/jzus.A2000399

Barandiarán Villegas LB, 2018. Sinkhole Development over Karstic Substratum. An MPM Approach. Universitat Politècnica de Catalunya, Barcelona, Spain.

Yin ZY, Wang P, Zhang FS, 2020. Effect of particle shape on the progressive failure of shield tunnel face in granular soils by coupled FDM-DEM method. Tunnelling and Underground Space Technology, 100:103394. https://doi.org/10.1016/j.tust.2020.103394

Yuan WH, Wang B, Zhang W, et al., 2019. Development of an explicit smoothed particle finite element method for geotechnical applications. Computers and Geotechnics, 106: 42-51.

https://doi.org/10.1016/j.compgeo.2018.10.010

Yuan WH, Wang HC, Liu K, et al., 2021. Analysis of large deformation geotechnical problems using implicit generalized interpolation material point method. Journal of Zhejiang University-SCIENCE A (Applied Physics \& Engineering), 22(11):909-923. https://doi.org/10.1631/jzus.A2100219

Zhang W, Yuan WH, Dai BB, 2018. Smoothed particle finiteelement method for large-deformation problems in geomechanics. International Journal of Geomechanics, 18(4): 04018010 . https://doi.org/10.1061/(ASCE)GM.1943-5622.0001079

Zhang X, 2014. Particle Finite Element Method in Geomechanics. PhD Thesis, The University of Newcastle, Australia.

Zhang X, Krabbenhoft K, Pedroso DM, et al., 2013. Particle finite element analysis of large deformation and granular flow problems. Computers and Geotechnics, 54:133-142. https://doi.org/10.1016/j.compgeo.2013.07.001

Zhang ZQ, Li YL, Zhu XY, et al., 2021. Meso-scale corrosion expansion cracking of ribbed reinforced concrete based on a 3D random aggregate model. Journal of Zhejiang University-SCIENCE A (Applied Physics \& Engineering), 
22(11):924-940.

https://doi.org/10.1631/jzus.A2100304

Zhang ZY, Jin XG, Luo W, 2019. Numerical study on the collapse behaviors of shallow tunnel faces under open-face excavation condition using mesh-free method. Journal of Engineering Mechanics, 145(11):04019085.
https://doi.org/10.1061/(ASCE)EM.1943-7889.0001661

Zheng G, Zhu R, Sun JB, et al., 2021. Numerical study on failure propagation between two closely spaced tunnels. Journal of Zhejiang University-SCIENCE A (Applied Physics \& Engineering), 22(11):894-908.

https://doi.org/10.1631/jzus.A2000502

\section{Introducing Guest Editor-in-Chief and Guest Editors:}

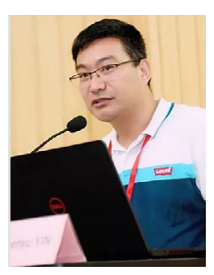

\section{Guest Editor-in-Chief}

Dr. Zhen-yu YIN has been an Editorial Board Member of Journal of Zhejiang University-SCIENCE A (Applied Physics \& Engineering) since 2019.

Dr. Zhen-yu YIN has been an Associate Professor of Geotechnical Engineering at The Hong Kong Polytechnic University (China) since 2018. Dr. YIN received his BEng in Civil Engineering from Zhejiang University (China) in 1997, followed by a 5-year engineering consultancy at the Zhejiang Jiahua Architecture Design Institute (China). Then, he obtained his MSc and PhD in Geotechnical Engineering at Ecole Centrale de Nantes (France) in 2003 and 2006, respectively. Dr. YIN worked at Helsinki University of Technology (Finland), the University of Strathclyde (UK), University of Massachusetts (USA), Shanghai Jiao Tong University (China), Tongji University (China), and Ecole Centrale de Nantes before moving to Hong Kong. Dr. YIN has published over 220 articles in peer reviewed international journals with an $H$-index of Web of Science of 43.

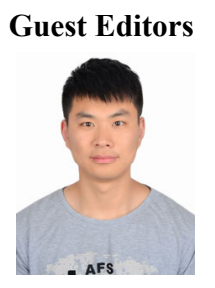

Dr. Yin-fu JIN,

Postdoctoral fellow

Department of Civil and Environmental

Engineering, The Hong Kong Polytechnic

University, Hong Kong, China

E-mail: yinfu.jin9019@gmail.com

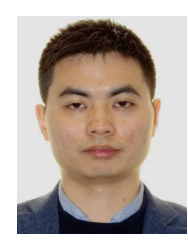

Dr. Xue ZHANG,

$\mathrm{PhD}$ Lecturer

Department of Civil Engineering and

Industrial Design, University of Liverpool,

Liverpool, UK

E-mail: xue.zhang2@liverpool.ac.uk 